\title{
USE OF ACRYLONITRILE-BUTADIENE-STYRENE FROM WASTE ELECTRIC AND ELECTRONIC EQUIPMENT WITHOUT AN ACCURATE PREVIOUS SEPARATION
}

\author{
Yamila V. Vazquez * and Silvia E. Barbosa
}

Planta Piloto de Ingeniería Química, PLAPIQUI (UNS-CONICET), CP: 8000, Camino "La Carrindanga" Km 7, Bahía Blanca, Argentina Departamento de Ingeniería Química, Universidad Nacional del Sur, CP: 8000, Av. Alem 1253, Bahía Blanca, Argentina

Article Info:

Received:

17 January 2018

Revised:

30 April 2018

Accepted:

16 June 2018

Available online:

30 June 2018

Keywords:

WEEE

ABS

Plastic recycling

Compatibilization strategies

\begin{abstract}
The aim of this work it to develop recycling strategies for Acrylonitrile-Butadiene-Styrene (ABS), coming from plastic WEEE stream, avoiding sorting by type. Self-compatibilization of ABS/HIPS blends, as well as the addition of Styrene-Butadiene-Styrene (SBS) as a compatibilizer to ABS/HIPS blends in order to improve mechanical properties, were studied. In this way, thermal behavior, mechanical performance and morphology of ABS/HIPS physical blends with two different proportions, $80 / 20$ and $50 / 50$, was analyzed comparatively with single ABS to assess self-compatibilization effectiveness. Obtained results indicate that ABS/HIPS self-compatibilization is effective. ABS can tolerate up to $50 \mathrm{wt} \%$ of HIPS conserving its properties with a slight improvement in ductility and strength. This allows a wider error in plastic sorting by type within plastic WEEE stream and consequently costs can be reduced. Same blends proportions with the addition of $2 \mathrm{wt} \%$ of SBS was also studied in comparison to their physical blends and single ABS. Mechanical properties of SBS-compatibilized blends were notably improved with respect to physical blends and consequently to ABS. Results are very promising for plastic WEEE recycling leading to a sustainable strategy that can promote the reuse of recycled ABS blended with other plastic WEEE instead of single ABS.
\end{abstract}

\section{INTRODUCTION}

Constant advances in high-tech products lead to an increment in electrical and electronic devices consumption, meaning that most of the replaced equipment are turned into scrap (Namias, 2013). The stream of waste from electrical and electronic equipment (WEEE) contains several valuable and recyclable materials like gold, silver, platinum, palladium, plastics and silica (Baldé et al., 2014; Buekens and Yang, 2014). While plastics are neither the main nor the most abundant, they occupy a lot of space in landfills because of their high volume due to low density and parts shape (Goodship and Stevels, 2012; Cui et al., 2003). Plastic from WEEE represents approximately $18 \mathrm{wt} \%$ of this waste stream consisting mainly of thermoplastics that can be recycled by reprocessing (Brennan et al., 2002; Bisio and Xanthos, 1995). For their recycling, they are generally chopped, washed and sorted by type involving relatively high costs (Baxter et al., 2014). Plastic resins from WEEE are similar which makes it very difficult to separate them by type using automatic sorting methods. There are several specific automatic techniques but their precision highly de- pends on plastic stream composition (WRAP, 2009). Near infrared spectroscopy (NIR) is the best known automatic method for plastic separation by type. However, its use for plastic WEEE classification is not optimum because these materials usually are dark colored making it difficult to classify by NIR. Also, the major amount of plastic WEEE contains styrenic resins with very similar molecular structures (like ABS and HIPS) and consequently, they are not well differentiated by NIR (Arends et al., 2015; Maris et al., 2015; WRAP, 2009). Also, the last problem strongly affects sorting by other techniques like density separation and impact milling (WRAP, 2009; Tall, 2000). Due to these reasons, and because devices used for automatic sorting are expensive and not easy to handle, lead to mainly manual sorting in the plastic recycling industry (Beigbeider et al., 2013). This is not optimum as the precision of this sorting method depends on human error and also, it can be hazardous and unhealthy for workers (Ceballos et al., 2014).

A sustainable option to manage plastics from WEEE would be to not separate WEEE plastics resins by type and recycle them together. This alternative could avoid sorting by type within plastic WEEE stream and consequently, re- 
duce recycling associated costs and promote it. It is well known, however, that direct melt blending of two or more thermoplastic resins causes phase segregation, low interfacial adhesion and consequently deteriorated mechanical properties (Utracki, 1991). Because of this, a specific compatibilization process is necessary to increases phase adhesion, reduce the interfacial tension, stabilizing morphology by inhibiting droplet coalescence and thus improving mechanical properties (Davis et al., 2000; Elmendorp et al., 1991; Wu, 1982).

An efficient blend compatibilization is the key to add value to mixed recycled plastics, but that is the challenge. Predominantly, plastics from e-scrap are complex composites with copolymers as a matrix and mineral particles (like calcium carbonate, carbon black, silica, etc.) as fillers (Hirayama et al., 2018; Vazquez and Barbosa, 2016; Buekens and Yang, 2014). These kind of materials also contain brominated substances as flame retardant additives making it even more difficult to recycle (Vazquez and Barbosa, 2016; Arnold et al., 2009). Within plastic WEEE stream, ABS (acrylonitrile-butadiene-styrene) and HIPS (high impact polystyrene) are two of the major components. ABS, is a block copolymer with good mechanical performance but its price is not as low as other plastics from e-scrap, like HIPS (Maris et al., 2015; Martinho et al., 2012). Both copolymers are styrenic resins which are very difficult to separate within plastic WEEE stream because of component similarities. In literature, there are several works of ABS/ HIPS blends compatibilization studies on both, virgin and plastic from WEEE resins. Peyro Rasero et al. (2015) used SEBS (Styrene-Ethylene-Butylene-Styrene) as a compatibilizer in order to improve virgin ABS/HIPS blends ductility, as this material has similar polymeric segments. Results evidenced an increment in elongation at break with tensile strength decrement. Also, Arnold et al. (2010) claims that in ABS/HIPS blends obtained from virgin and plastic WEEE resins, final properties are deteriorated with respect to the initial materials and consequently, has poor added value. On the other hand, results obtained by Tarantilli et al. (2010) performing analysis on virgin ABS/HIPS blends shows an opposite behavior in which final properties were slightly improved.

Taking into account that plastic WEEE resins are composites as described above, conclusions obtained by working with virgin resins blends cannot be directly extrapolated to plastic blends from e-scrap. In this way, several authors obtained promising results working with ABS/HIPS blends from WEEE. Brennan et al., (2002) concluded that small amounts of ABS in HIPS and vice versa, improve tensile final mechanical properties respect on the corresponding properties of the major component in the blend. Moreover, de Souza et al. (2016) work evidenced that strength and stiffness of ABS/HIPS blends decrease with HIPS amount while ductility is improved. Also, their study indicates that smaller particle size of materials for injection molding, results in better mechanical performance. They conclude that ABS/HIPS recycled blends could lead to a decrease of processing costs.

Taking into account this background it is important to note that plastic WEEE used in some studies came from specific Electric and Electronic Equipment (EEE) sources (like informatic appliances) instead of a general plastic WEEE stream, that includes several EEE sources. General plastic stream from e-scrap is more conservative. As a consequence of using different kind of plastic sources, results are not always the same in studies of ABS/HIPS blends from plastic WEEE. All the studies have in common an important conclusion, however, which is to continue working these in order to find a sustainable solution to the recycling of these WEEE styrenic resins.

The aim of this work is to study direct melt blending of ABS with HIPS, both from WEEE, in order to develop recycling strategies for ABS avoiding plastic sorting by type within plastic WEEE stream using these blends as a direct replacement in same applications of single recycled $A B S$. In this sense, self and addition compatibilization of ABS/ HIPS blends are studied. Self-compatibilization analysis allows to assess how much HIPS can be tolerated by ABS while conserving its properties (at least). Consequently, a wider error in plastic sorting by type within plastic WEEE stream can be accepted and then, the associated costs of plastic classification process can be reduced. Furthermore, the addition of $2 \mathrm{wt} \%$ Styrene-Butadiene-Styrene (SBS) as a compatibilizer of ABS/HIPS blends is also analyzed in order to improve phase adhesion and thus mechanical performance.

Two different proportion, $80 / 20$ and 50/50, of ABS/HIPS are considered as base physical blends for both types of compatibilization studies. Compatibilization effectiveness is assessed through a comparative evaluation of thermal behavior, phase morphology and mechanical performance of all blends prepared and single ABS.

\section{EXPERIMENTAL}

\subsection{Materials}

ABS and HIPS from e-scrap were used as initial materials. They were kindly provided by Ecotécnica del Pilar S.R.L from Argentina. Each plastic sample used in this work were obtained by mixing 10 powder portions of $500 \mathrm{~g}$ from different places of a $25 \mathrm{Kg}$ commercial bag in order to have a representative sample of each initial plastic e-scrap. A block copolymer of styrene-butadiene, SBS KIBITON ${ }^{\circledR}$ Q-Resin PB-5903 from CHI MEI Corporation with a MFI of $10 \mathrm{ml} / 10 \mathrm{~min}$ (ISO $1133-200^{\circ} \mathrm{C} \times 5 \mathrm{KG}$ ) was used as compatibilizer.

\subsection{Characterization}

\subsubsection{Blending}

ABS/HIPS physical blends with $80 / 20$ and $50 / 50$ weight proportion were prepared in a batch mixer (Brabender Plastograph W50) under nitrogen atmosphere at $180^{\circ} \mathrm{C}$ and 30 rpm for 10 minutes. Physical blends with the addition of $2 \mathrm{wt} \%$ of SBS (compatibilized blends) were prepared under the same conditions. Batch mixing was used to simulate the expected processing in a twin-screw extruder as Brennan et al. (2002) suggested. In order to obtain a more representative and homogeneous blend, the following routine was performed for initial material and blends process- 
ing: a) each blend was replicated three times, b) resulting blends were milled and mixed and, c) with these chopped materials flexural specimens were obtained by compression molding. Table 1 summarizes the names and concentration of all blends prepared.

\subsubsection{Glass transition}

Glass transition temperatures $\left(T_{q}\right)$ of initial materials and blends were determined by Modulated Differential Scanning Calorimetry (MDSC $\AA$ ) in a Discovery DSC from TA Instruments. An initial scanning was performed to erase thermal history followed by a cooling step and a second heating. Heat/cool/heat test were performed with a rate of $1^{\circ} \mathrm{C} / \mathrm{min}$ from $60^{\circ} \mathrm{C}$ to $180^{\circ} \mathrm{C}$. Second heating results were used to determine $T_{g}$ values and perform the comparative analysis.

\subsubsection{Mechanical properties}

Flexural tests were performed at room temperature in the Universal Testing Machine Instron 3369. Test conditions and specimen dimensions were determined according to ASTM D790-03 standard for plastic. Flexural conditions were: rate of crosshead motion of $1.28 \mathrm{~mm} /$ min, support span of $48 \mathrm{~mm}$ and midspan deflection of $6.4 \mathrm{~mm}$. Specimens of $100 \times 10 \times 3 \mathrm{~mm}$ were cut from plates prepared by compression molding at $180^{\circ} \mathrm{C}$. Eight specimens for each sample were measured. Elastic modulus, ultimate strength, ductility and toughness were assessed from stress-strain curves.

\subsubsection{Blend morphology}

Blends morphology analysis was performed by Scanning Electron Microscopy (SEM) in a LEO EVO 40 XVP electron microscope, operated at $10 \mathrm{kV}$. Samples were cryofractured under liquid nitrogen, mounted on bronze stubs and then, coated with a gold layer $(\sim 30 \AA)$ using an argon plasma metallizer (sputter coater PELCO 91000).

\section{RESULTS AND DISCUSSION}

In previous works it was demonstrated through High Resolution Modulated Thermogravimetric Analysis ( $\mathrm{Hi}-$ $\left.\operatorname{Res}^{\mathrm{TM}} \mathrm{MTGA}^{\mathrm{TM}}\right)$ that the ABS used in the present study contains $8.8 \mathrm{wt} \%$ of mineral fillers and an acrylonitrile/butadiene/styrene (AN/Bu/St) proportion of 32.5/30.6/28.1. Meanwhile, HIPS has 4.4 wt\% of fillers with an AN/Bu/ St proportion of $6.0 / 28.8 / 60.6$, evidence that there is not neat separation of plastics WEEE by type, as it was expected. This fact also indicates that, plastics WEEE are composites with complex polymeric matrix. Additionally, it was determined that the total amount of bromine is under the maximum admissible content according European Directive about hazardous substances in WEEE (Vazquez and Barbosa, 2016 and 2017; European Union, 2011). This previous characterization is very important because mechanical behavior of ABS/HIPS blends will be determined by components proportion and their interaction with fillers.

Changes in glass transition temperature $\left(T_{q}\right)$ give a first approximation of compatibilization effectiveness in poly- mer blends. In compatibilized blends, because of phase interaction enhancement, it is expected that $T_{g}$ values of each component tends to converge (Utracki, 1991). $T_{g}$ of ABS and HIPS from WEEE and all blends prepared are listed in Table 2 while the corresponding thermograms are presented in Figure 1.

It can be observed that $\mathrm{A} 50 / \mathrm{H} 50$ blend has a $\mathrm{T}_{\mathrm{g}}$ of $94.6^{\circ} \mathrm{C}$, which value is between ABS and HIPS $T_{g}^{\prime}$ 's. This fact could indicate phase interaction improvement and consequently an effective self-compatibilization. On the other hand, $\mathrm{A} 80 / \mathrm{H} 20$ blend has two $\mathrm{T}_{\mathrm{g}}$, one at $94.9^{\circ} \mathrm{C}$ and the other at $101.2^{\circ} \mathrm{C}$. The first one is between glass transition temperatures of initial materials, probably indicating that styrene phases present in both matrix has interacted. However, the second $T_{g}$ could evidence phase interaction decrement. It is probable that, during blending, initial AN domains suffer a coalescence and then, AN glass transition is manifesting by itself (Zhang et al., 2011). Despite this, it is not possible to ensure a non-effective compatibilization. For this reason, in order to corroborate claims made from thermal behavior, mechanical properties study along with morphology analysis is performed.

Mechanical behavior allows to better comprehend phase interaction and conclude respect to compatibilization efficiency. Changes in properties measured at high strain, like ultimate strength $\left(\sigma_{u}\right)$ and ductility $\left(\varepsilon_{b}\right)$ gives a measurement of compatibilization effectiveness. Toughness, the necessary energy for a material to break, is another property sensitive to compatibilization. Meanwhile, the Elastic Modulus (E), which gives an idea of material stiffness, is a zero-strain property and only depends on the internal structure of components and their relative proportions. For this reason, this property does not give any specific information about phase interaction (Utracki,

TABLE 1: Names and concentration of all blends prepared.

\begin{tabular}{l|c|c}
\multicolumn{1}{c}{ Name } & ABS/HIPS (wt\%/wt\%) & SBS (wt\%) \\
\hline Physical Blends & $80 / 20$ & 0 \\
\hline A80/H20 & $50 / 50$ & 0 \\
\hdashline A50/H50 & & \\
\hline Compatibilized Blends & & 2 \\
\hline A80/H20-2SBS & $78.4 / 19.6$ & 2 \\
\hline A50/H50-2SBS & $49 / 49$ & \\
\hline
\end{tabular}

TABLE 2: Glass transition temperatures of all blends prepared determined by MDSC (error < 5\%).

\begin{tabular}{l|c}
\multicolumn{1}{c}{ Sample } & Tg $\left({ }^{\circ} \mathbf{C}\right)$ \\
\hline HIPS & 93.7 \\
\hline ABS & 95.2 \\
\hline SBS & 101.1 \\
\hline A80/H20 & $94.2 / 101.2$ \\
\hline A50/H50 & 94.6 \\
\hline A80/H20-2SBS & $*$ \\
\hline A50/H50-2SBS & 95.0 \\
\hline
\end{tabular}

* Transitions not clear 


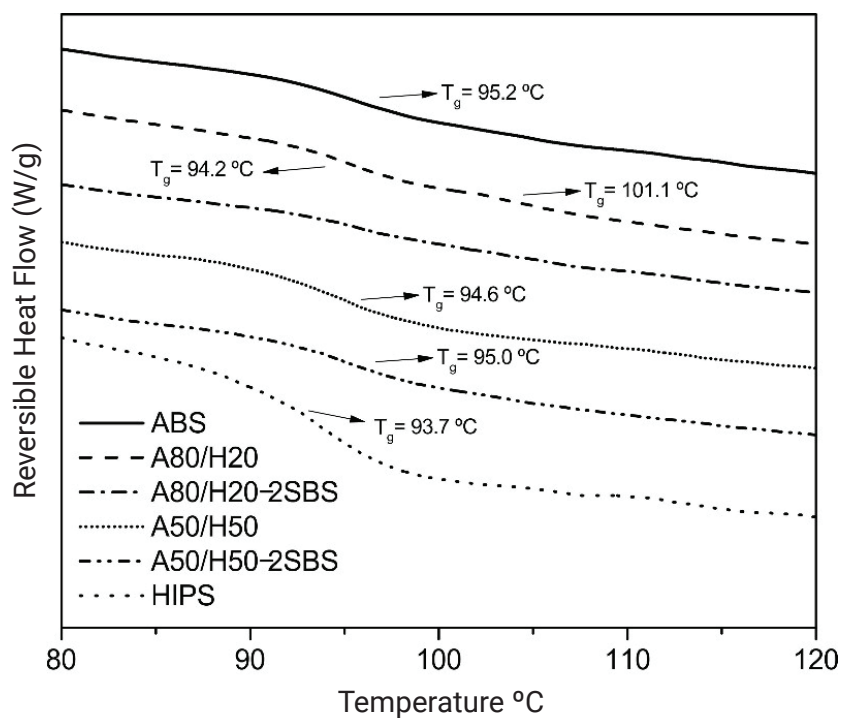

FIGURE 1: Thermograms (Exo-up) of ABS, HIPS and all blends prepared.

1991). Therefore, a thermal and mechanical behavior analysis combined with a morphology study allows to evaluate compatibilization effectiveness.

Figure 2 shows flexural stress-strain curves of ABS, HIPS and all blends prepared while mechanical properties $\left(\mathrm{E}, \sigma_{\mathrm{u}^{\prime}} \varepsilon_{\mathrm{b}}\right.$ and toughness) are detailed in Table 3. It can be observed that $\mathrm{A} 80 / \mathrm{H} 20$ curve is very similar to $\mathrm{ABS}$ one. Also, an increase in stiffness and in less proportion in ductility and strength can be observed. This is evidence of the AN phase redistribution observation made from thermal analysis.

On the other hand, despite the coalescence of AN domains, it is possible to detect the strength and ductility increase in $\mathrm{A} 80 / \mathrm{H} 20$ blend with respect to $\mathrm{ABS}$ which indicates phase adhesion improvement and therefore self-compatibilization effectiveness. This is consistent with morphological aspects of $\mathrm{ABS}$ and $\mathrm{A} 80 / \mathrm{H} 20$ blend. Figure 3 shows cryofracture surface SEM micrograph of ABS while the corresponding A80/H20 blend SEM image is presented in Figure 4a. Both surfaces present sharpened edges, typical of a brittle fracture, but they are more pronounced in ABS. Also, it is possible to note that $A 80$ /

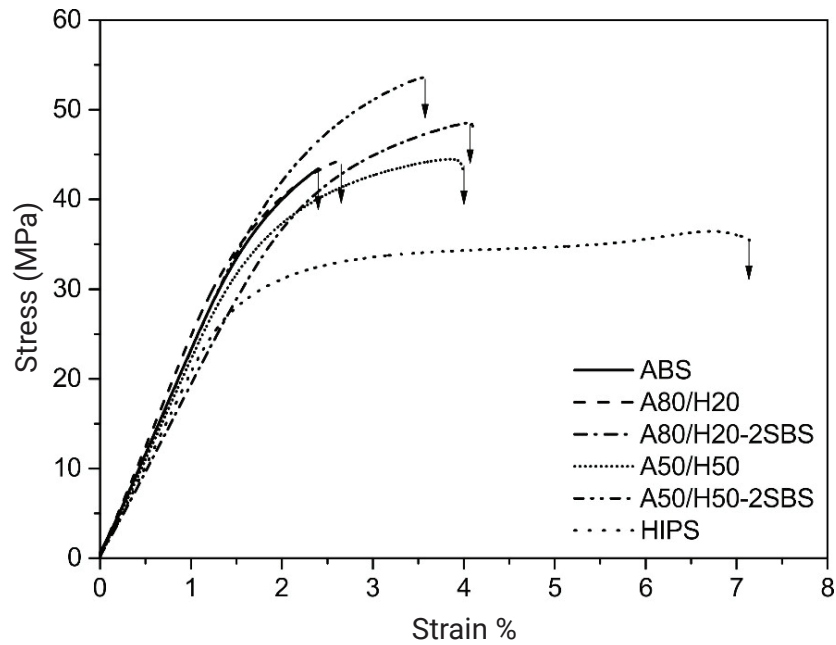

FIGURE 2: Stress-strain curves from flexural tests of ABS, HIPS and all blends prepared.

$\mathrm{H} 20$ has bigger AN domains than ABS. This evaluation completely agrees with the coalescence of initial AN domains in ABS during processing resulting in strength improvement. Moreover, there are other small domains that correspond to rubbery ones (Bu phase) which form from rubber recoil after fracture therefore increasing ductility. In this sense, the obtained final properties of $\mathrm{A} 80 / \mathrm{H} 20$ blends indicate that they could be used in housing manufacturing industry for Electrical and Electronic Equipment, instead of single ABS.

Regarding mechanical performance of A50/H50 blend (Figure 2 and Table 3), it is clear that fillers still govern its behavior at low deformations since stiffness did not change. The rubbery phase exists at higher deformations, however, resulting in lower stress in the A50/H50 blend than in ABS for same deformation values. It is possible that during blending rubbery phase had been relocated at the filler/matrix interphase reducing filler effect and increasing ductility (Figure 3). Changes observed in properties, particularly the notable improvement in ductility, evidenced by phase adhesion enhancement shown by glass transition analysis illustrate effective compatibilization. This hypothesis can be corroborated from the comparison between cryofracture surface SEM micrographs of A50/H50 (Figure

TABLE 3: Flexural mechanical properties $\left(E, \sigma_{u}, \varepsilon_{b}\right.$ and toughness) of ABS, HIPS, SBS and all blends prepared according ASTM D790-03.

\begin{tabular}{|c|c|c|c|c|}
\hline Sample & $\mathrm{E}(\mathrm{MPa})$ & $\sigma_{\mathrm{u}}(\mathrm{MPa})$ & $\varepsilon_{\mathrm{b}}(\%)$ & Toughness $\left(\mathrm{J} / \mathrm{m}^{3}\right)$ * \\
\hline ABS ${ }^{a, b}$ & $2339 \pm 29$ & $43.4 \pm 1.7$ & $2.44 \pm 0.16$ & $0.63 \pm 0.07$ \\
\hline HIPS $a, b$ & $2068 \pm 208$ & $35.6 \pm 1.6$ & $6.96 \pm 0.26$ & $2.25 \pm 0.16$ \\
\hline $\mathrm{SBS}^{\mathrm{b}}$ & $670 \pm 122$ & $20.1 \pm 3.2$ & Not break & $1.71 \pm 0.22$ \\
\hline $\mathrm{A} 80 / \mathrm{H} 20 \mathrm{a}$ & $2385 \pm 113$ & $43.7 \pm 2.7$ & $2.69 \pm 0.14$ & $0.67 \pm 0.13$ \\
\hline $\mathrm{A} 50 / \mathrm{H} 50^{\mathrm{b}}$ & $2148 \pm 56$ & $43.6 \pm 2.3$ & $4.03 \pm 0.68$ & $1.40 \pm 0.18$ \\
\hline A80/H20-2SBS a & $1888 \pm 57$ & $47.6 \pm 2.0$ & $4.27 \pm 0.61$ & $1.36 \pm 0.31$ \\
\hline A50/H50-2SBS & $2312 \pm 52$ & $53.1 \pm 0.6$ & $3.45 \pm 0.25$ & $2.26 \pm 0.12$ \\
\hline
\end{tabular}

a Vazquez and Barbosa, 2016.

b Vazquez and Barbosa, 2017.

* Toughness is the energy per volume necessary for sample break under flexural test. It is calculated as the area under stress-strain curves (up to break) obtained from this test. 


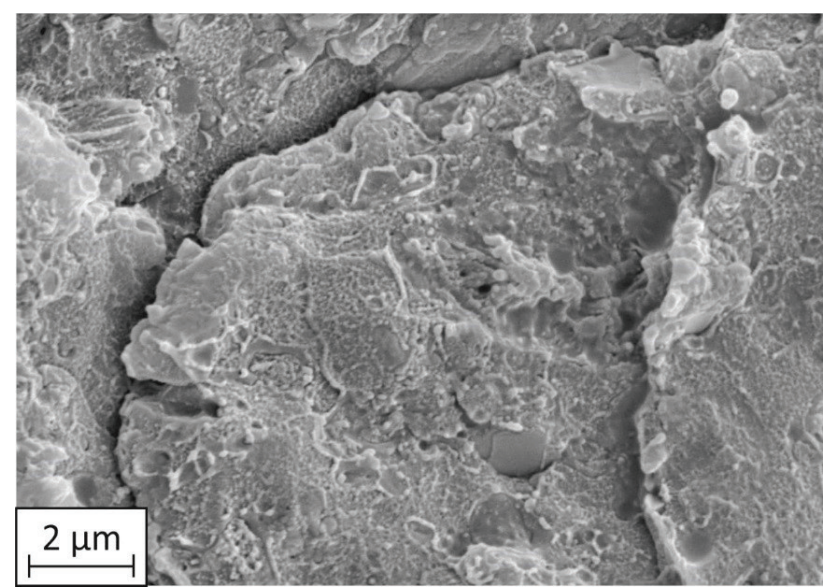

FIGURE 3: Cryofracture surface SEM micrograph of ABS (20000x).

4b) and ABS (Figure 3). Brittle fracture is less notable in A50/H50 blend in comparison with ABS. Also, it is possible to note that $\mathrm{A} 50 / \mathrm{H} 50$ blend surface presents domains with fillers inside them agreeing with data from mechanical analysis. In this way, considering mechanical performance improvement with respect to the $A B S$, this blend can also be used as a replacement of ABS in EEE housing manufacturing industry. In addition, the higher ductility of $\mathrm{A} 50 / \mathrm{H} 50$ blend allows use in a wider variety of applications.

In order to improve final properties and thus compatibilization effectiveness, the addition of $2 \mathrm{wt} \%$ of SBS as a compatibilizer to ABS/HIPS physical blends was analyzed. SBS is a copolymer with a typical rubbery behavior with low strength and stiffness. This copolymer was selected for having similar structure to ABS and HIPS (its molecules contain $\mathrm{St}$ and $\mathrm{Bu}$ ). It is expected that $\mathrm{St}$ and Bu blocks interacts with those from ABS and HIPS improving their compatibility. Compatibilization effectiveness will depend on the relative ABS/HIPS proportion, among others factors like the presence of fillers.

Glass transition temperatures of compatibilized blends with SBS are listed in Table 2 while the corresponding thermograms are shown in Figure 1. In A80/H20-2SBS blend it was very difficult to assess a $T_{g}$ because transitions were not well defined (Figure 1). Unfortunately, this does not give any evidence about phase interaction and therefore, it is impossible to ensure compatibilization effectiveness. On the other hand, A50/H50-2SBS blend shows a single $\mathrm{T}_{\mathrm{g}}$ of $95.0^{\circ} \mathrm{C}$, slightly higher than the $\mathrm{A} 50 / \mathrm{H} 50$ one. The $\mathrm{T}_{\mathrm{g}}$ of this blend presents an increment respect to A50/H50 physical blend one, as expected because of the addition of SBS which has a $T_{g}$ of $101.1^{\circ} \mathrm{C}$. This behavior indicates an improvement in phase interaction and a possible effective compatibilization. In order to assess SBS compatibilization effectiveness, mechanical properties and morphology of compatibilized blends were comparatively analyzed with ABS and physical blends.

Flexural mechanical behavior of compatibilized blends compared with physical ones and ABS are presented in Figure 2 while the assessed mechanical properties are listed in Table 3. A80/H20-2SBS stress-strain curve illustrates an increment in ductility and strength with respect to $A B S$ and even to the physical blend. The increase in both properties indicates an improvement in phase adhesion which shows evidence of an effective compatibilization. On the other hand, A50/H50-2SBS present a notable increase in $\sigma u$ and $\varepsilon b$ respect to $A B S$, however, $\varepsilon b$ decrease respect to the physical blend although within the margin of error. This could be explained assuming that the addition of SBS produces the coalescence of rubbery domains and fillers unmasking. This last fact agrees with the higher stress in the whole range of deformation of A50/H50-2SBS blend in comparison with $\mathrm{ABS}$ and the corresponding physical blend. From mechanical behavior analysis it is possible to say that both SBS-compatibilized blends could be used as a direct replacement of separated recycled ABS and also of their corresponding physical blend, with improved resistance.

In order to corroborate all assumptions made from mechanical properties analysis, a morphological study was performed. Cryofractures surface SEM micrographs included in Figure 4 allows an analysis of compatibilized blends morphology. Regarding A80/H20-2SBS blend (Figure $4 \mathrm{c}$ ), fragile fracture edges are evident just like in the A80/H20 blend (Figure 4a). Also, there are well distributed and dispersed domains with smaller sizes demonstrating an improvement in phase adhesion. This is consistent with the increment in ductility and strength (Table 3). On the other hand, the A50/H50-2SBS blend cryofracture surface (Figure 4d) shows more noticeable brittle fracture than the A50/H50 physical blend as illustrated by the sharpened edges. This morphology is consistent with a stiffer and more resistant material, agreeing with data from mechanical properties analysis. In addition, fillers are more evident and some of them are located inside rubbery domains. Also, domains and fillers are well distributed along fracture surfaces. These facts show rubbery phase redistribution by the addition of SBS, as shown from mechanical performance analysis.

\section{CONCLUSIONS}

Self-compatibilization as well as, addition compatibilization with 2 wt\% SBS of ABS/HIPS physical blends from plastic WEEE stream were explored in order to design a sustainable strategy to recycle this kind of e-scrap with higher profitability. Self-compatibilization results indicate that ABS can tolerate up to $50 \mathrm{wt} \%$ of HIPS with an improvement in ductility and strength. Furthermore, the addition of $2 \mathrm{wt} \%$ of SBS to A50/H50 blend shows an increase of $22 \%$ and $40 \%$ in mechanical strength and ductility with respect to ABS. Also, the strength of A50/ H50 physical blend was improved $22 \%$ with SBS addition, while ductility was slightly reduced. Furthermore, the addition of 2 wt $\%$ SBS to A80/H20 blend increase $9 \%$ strength and $65 \%$ ductility with respect to both $A B S$ and physical blend.

These results are very promising for mixed plastic WEEE recycling. It was demonstrated that recycled ABS could be replaced in the housing manufacturing industry of Electrical and Electronic Equipment by materials resulting from ABS mixed with up to $50 \mathrm{wt} \%$ of HIPS. These materi- 

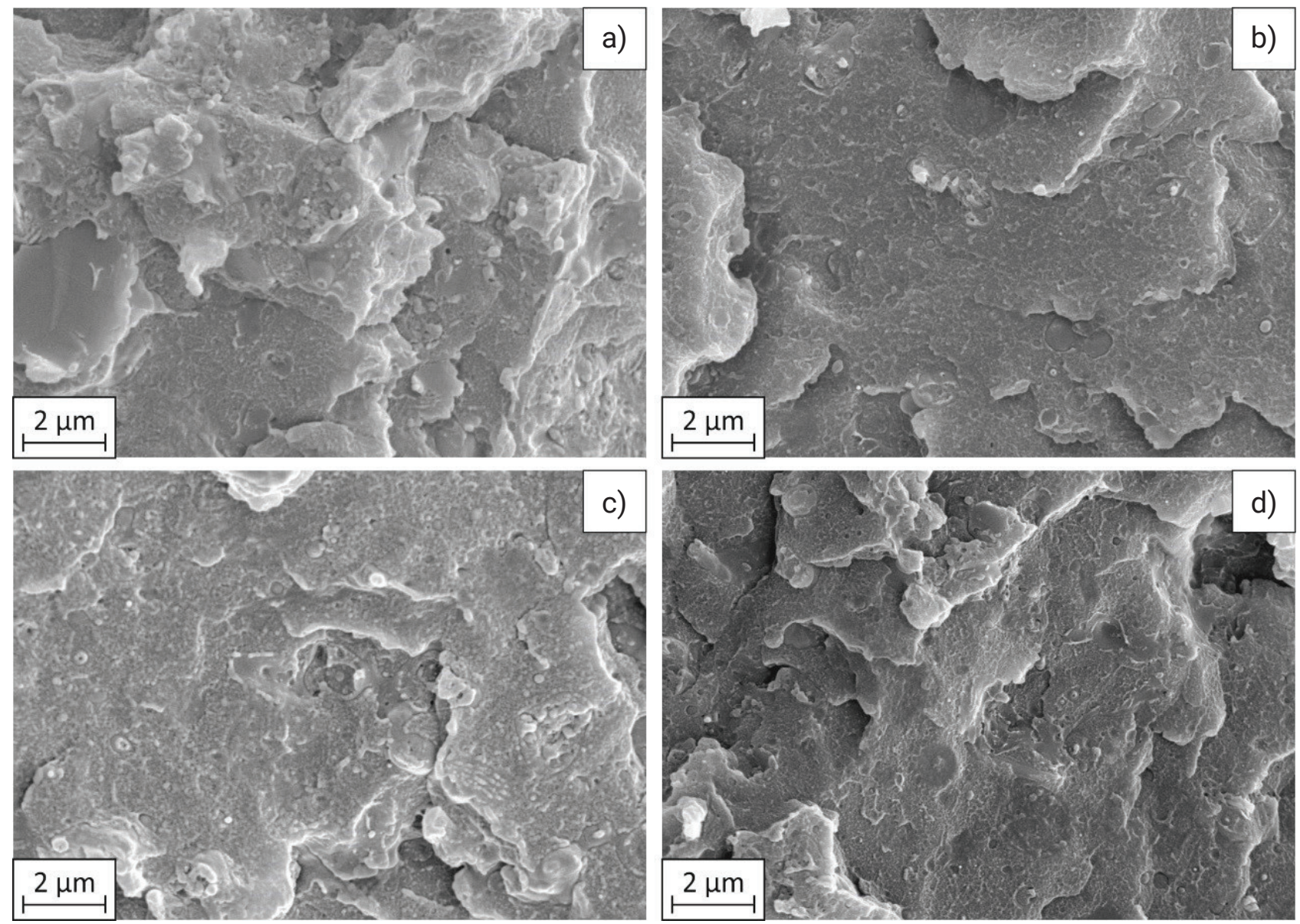

FIGURE 4: Cryofracture surface SEM micrographs (20000x) of a) A80/H20, b) A50/H50, c) A80/H20-2SBS and d) A50/H50-2SBS.

als can be even more improved with the addition of a small amount of a low cost compatibilizer. Clearly, the proposed strategies are effective because significant products are obtained through an easy and low-cost process: direct melt blending.

\section{ACKOWNLEDGEMENTS}

The authors are grateful to CONICET (Argentine National Research Council), ANPCyT (National Agency for Scientific and Technological Promotion) and UNS (South National University) for their technical and financial support.

\section{REFERENCES}

Arends D., Schlummer M., Mäurer A., Markowski J., Wagenknecht U. (2015). Characterization and materials flow management for waste electrical and electronic equipment plastics from German dismantling centers. Waste Management \& Research, 33(9), 775784.

Arnold J C, Watson T, Alston S, Carnie M, Glover C. (2010) The use of FTIR mapping to assess phase distribution in mixed and recycled WEEE plastics. Polymer Testing, 29: 459-470.

Baldé C. P., Wang F., Kuehr R., Huisman J. (2015). The global e-waste monitor - 2014, United Nations University. IAS-SCYCLE, Bonn, Germany.

Baxter J., Wahlstrom M., Zu Castell-Rüdenhausen M., Fråne, A., Stare M., Løkke, S., Pizzol M. (2014). Plastic value chains: Case: WEEE (Waste Electric and electronic equipment) in the Nordic region. Nordic Council of Ministers, TemaNord, Denmark.
Beigbeder J., Perrin D., Mascaro J. F., Lopez-Cuesta J. M. (2013). Study of the physicochemical properties of recycled polymers from waste electrical and electronic equipment (WEEE) sorted by high resolution near infrared devices. Resources Conservation \& Recycling, 78: 105-114

Bisio A. L., Xanthos M. How to Manage Plastics Wastes: Technology and Market Opportunities. New York: Hanser, 1995.

Brennan L. B., Isaac D. H., Arnold J. C. (2002). Recycling of Acrylonitrile-Butadiene-Styrene and High- Impact Polystyrene from Waste Computer Equipment. Journal of Applied Polymer Science, 86(3): 572-578.

Buekens A., Yang J. (2014). Recycling of WEEE plastics: a review. Journal of Material Cycles and Waste Management, 16(3):415-34.

Ceballos D., Chen L., Page E., Echt A., Oza A., Ramsey J. Health Hazard Evaluation Report: Evaluation of Occupational Exposures at an Electronic Scrap Recycling Facility. U.S. Department of Health and Human Services, Centers for Disease Control and Prevention, National Institute for Occupational Safety and Health. Cincinnati, Ohio: NIOSH, 2014.

Cui J., Forssberg E. (2003). Mechanical recycling of waste electric and electronic equipment: a review. Journal of Hazardous Materials, 99: 243-263.

Davis B. D., Paul D. R., Bucknall C. B. Polymer blends, vol. 1. New York: Wiley, 2000. pp. 501-538

De Souza A. M. C., Cucchiara M. G., Ereio A. V. (2016). ABS/HIPS blends obtained from WEEE: Influence of processing conditions and composition. Journal of Applied Polymer Science, 133(34). DOI: $10.1002 /$ app.43831.

Elmendorp J. J., Van der Vegt A. K., Utraki L. A. Two-phase polymer systems. Munich: Hanser, 1991. pp. 165-183.

European Union (2011). Directive 2011/65/EC of the European Parliament and of the Council of 8 June 2011 on the restriction of the use of certain hazardous substances in electrical and electronic equipment (recast), RoHS 2. Official Journal of the European Union, 174: 88-110. 
Goodship V., Stevels A. (2012). Waste Electrical and Electronic Equipment (WEEE) Handbook. Woodhead, USA.

Hirayama D., Saron C. (2018). Morphologic and mechanical properties of blends from recycled acrylonitrile-butadiene-styrene and high-impact polystyrene. Polymer, 135: 271-278.

Maris E., Botané P., Wavrer P., Froelich D. (2015). Characterizing plastics originating from WEEE: a case study in France. Mineral Engineering, 76: 28-37.

Martinho G., Pires A., Saraiva L., Ribeiro R. (2012). Composition of plastics from waste electrical and electronic equipment (WEEE) by direct sampling. Waste Management, 32: 1213-1217.

Namias J. (2013). The Future of Electronic Waste Recycling in the United States: Obstacles and Domestic Solutions. Department of Earth and Environmental Engineering, Columbia University, USA.

Peydro Rasero M. A., Garcia F. P., Navarro Vidal. R., Crespo Amoros J. E. (2015). Influence of styrene-ethylene-butylene-styrene on the properties of acrylonitrile butadiene styrene-high-impact polystyrene blends. Journal of Elastomers \& Plastics, 47(5): 449-62.

Tarantili P. A., Mitsakaki A. N., Petoussi M. A. (2010). Processing and properties of engineering plastics recycled from waste electrical and electronic equipment (WEEE). Polymer Degradation and Stability, 95(3):405-410
Tall S. (2000). Recycling of mixed plastic waste. Doctoral dissertation, Institutionen för polymerteknologi. Department of Polymer Technology, Royal Institute of Technology Stockholm, Sweden.

Utracki L. A. (1991). Polymer Alloys and Blends: State of the Art. National Research Council Canada, Industrial Materials Institute.

Vazquez Y. V; Barbosa S. E. (2016). Recycling of mixed plastic waste from electrical and electronic equipment. Added value by compatibilization. Waste Management, 53: 196-203.

Vazquez Y. V; Barbosa S. E. (2017). Process Window for Direct Recycling of Acrylonitrile-Butadiene-Styrene and High-Impact Polystyrene from Electrical and Electronic Equipment Waste. Waste Management, 50: 403-408.

WRAP(2009). Separation of mixed WEEE plastics final report(WRAPProject MDD018 and MDD023). Report prepared by Axion Consulting.

Wu S. Polymer interfaces and adhesion. New York: Marcel Dekker, 1982.

Zhang C., Guo Y., Priestley R. D. (2011). Glass transition temperature of polymer nanoparticles under soft and hard confinement. Macromolecules, 44(10): 4001-4006. 